\title{
Impact of paced left ventricular dyssynchrony on left ventricular reverse remodeling after cardiac resynchronization therapy
}

Citation for published version (APA):

Gauthey, A., Willemen, E., Lumens, J., Ploux, S., Bordachar, P., Ritter, P., Prinzen, F. W., Lejeune, S., Pouleur, A-C., Garnir, Q., Marchandise, S., Scavee, C., Wauters, A., \& De Waroux, J-B. L. P. (2020). Impact of paced left ventricular dyssynchrony on left ventricular reverse remodeling after cardiac resynchronization therapy. Journal of Cardiovascular Electrophysiology, 31(2), 494-502. https://doi.org/10.1111/jce.14330

Document status and date:

Published: 01/02/2020

DOI:

$10.1111 /$ jce. 14330

Document Version:

Publisher's PDF, also known as Version of record

\section{Document license:}

Taverne

Please check the document version of this publication:

- A submitted manuscript is the version of the article upon submission and before peer-review. There can be important differences between the submitted version and the official published version of record.

People interested in the research are advised to contact the author for the final version of the publication, or visit the DOI to the publisher's website.

- The final author version and the galley proof are versions of the publication after peer review.

- The final published version features the final layout of the paper including the volume, issue and page numbers.

Link to publication

\footnotetext{
General rights rights.

- You may freely distribute the URL identifying the publication in the public portal. please follow below link for the End User Agreement:

www.umlib.nl/taverne-license

Take down policy

If you believe that this document breaches copyright please contact us at:

repository@maastrichtuniversity.nl

providing details and we will investigate your claim.
}

Copyright and moral rights for the publications made accessible in the public portal are retained by the authors and/or other copyright owners and it is a condition of accessing publications that users recognise and abide by the legal requirements associated with these

- Users may download and print one copy of any publication from the public portal for the purpose of private study or research.

- You may not further distribute the material or use it for any profit-making activity or commercial gain

If the publication is distributed under the terms of Article 25fa of the Dutch Copyright Act, indicated by the "Taverne" license above, 


\title{
Impact of paced left ventricular dyssynchrony on left ventricular reverse remodeling after cardiac resynchronization therapy
}

\author{
Anaïs Gauthey $\mathrm{MD}^{1}$ (] | Erik Willemen $\mathrm{MSc}^{2}$ | Joost Lumens $\mathrm{PhD}^{2}$ (1) | \\ Sylvain Ploux MD, PhD $^{3}$ | Pierre Bordachar MD, PhD $^{3}$ | Philippe Ritter MD $^{3}$ | \\ Frits W. Prinzen $\mathrm{PhD}^{2}$ | Sibille Lejeune $\mathrm{MD}^{1}$ | Anne-Catherine Pouleur MD, $\mathrm{PhD}^{1}$ | \\ Quentin Garnir MD ${ }^{1}$ | Sébastien Marchandise $M^{1}$ | Christophe Scavée MD $^{1}$ | \\ Aurélien Wauters MD, $\mathrm{PhD}^{1}$ | Jean-Benoit le Polain de Waroux MD, $\mathrm{PhD}^{1}$
}

\begin{abstract}
${ }^{1}$ Division of Cardiology, Cliniques Universitaires Saint-Luc, Université Catholique de Louvain, Brussels, Belgium

${ }^{2}$ Cardiovascular Research Institute Maastricht (CARIM), Maastricht University Medical Center, Maastricht, The Netherlands

${ }^{3}$ IHU LYRIC (Institut de Rythmologie et Modélisation Cardiaque), Université de Bordeaux, Pessac, France

\section{Correspondence}

Anaïs Gauthey, MD, Division of Cardiology, Cliniques Universitaires Saint-Luc, Université Catholique de Louvain, Avenue Hippocrate, 10, B-1200 Brussels, Belgium.

Email: anaisgauthey@gmail.com

Disclosures: None.

Funding information

This study was supported by the Dr Dekker Program of the Dutch Heart Foundation (Grant 2015T082 to JL), the Netherlands Organization for Scientific Research (NWO-ZonMw, VIDI Grant 016.176.340 to $\mathrm{JL})$, and the ERA-Net ERACoSysMed program (PUSHCART to JL and FWP). FWP reports research grants from Medtronic, Abbott, Biotronik, Microport CRM, Biosense Webster, and EBR Systems. JL reports research grants from Medtronic
\end{abstract}

\begin{abstract}
Introduction: We investigated whether pacing-induced electrical dyssynchrony at the time of cardiac resynchronization therapy (CRT) device implantation was associated with chronic CRT response.

Methods and Results: We included a total of 69 consecutive heart failure patients who received a CRT device. Left (LVp-RVs) and right (RVp-LVs) pacing-induced interlead delays were measured intraoperatively and used to determine if there was paced left ventricular (LV) dyssynchrony, defined as present when LVp-RVs is larger than RVp-LVs. CRT response was defined as a reduction in $\mathrm{LV}$ end-systolic volume $\geq 15 \%, 6$ months after implantation. Paced left ventricular dyssynchrony (PLVD) was associated with ischemic cardiomyopathy (ICM) $\left(\chi^{2}: 8 ; P=.005\right)$ but not with QRS morphology nor with pacing lead positions. In a univariate analysis, PLVD (odds ratio [OR], 6.53; 95\% confidence interval [CI], 2.2-18.9; $P=.001)$, atypical left bundle branch block (LBBB) (OR, 3.3; $95 \% \mathrm{Cl}$, 1.2-9.4; $P=.022)$, and ICM (OR, 5.2; 95\% CI, 1.6-17; $P=.006)$ were associated with nonresponse. In a multivariate analysis, both PLVD (OR, 9.74; 95\% Cl, 2.8-33.9; $P<.0001)$ and atypical LBBB (OR, 5.6; 95\% Cl, 1.5-20.3; $P=.009)$ were independently associated with nonresponse. Adding PLVD to a model based on QRS morphology provided a significant and meaningful incremental value to predict LV reverse remodeling after CRT $\left(\chi^{2}\right.$ to enter: $\left.8 ; P<.005\right)$. Computer simulations corroborate these findings by showing that, while intrinsic electrical dyssynchrony is a prerequisite, the level of pacing-induced dyssynchrony modulates acute CRT response.
\end{abstract}


Conclusion: In addition to the intrinsic electrical substrate, PLVD is strongly associated with less LV reverse remodeling, demonstrating that measuring the electrical substrate during pacing has additional value for prediction of CRT response in an already well-selected patient population.

\section{KEYWORDS}

cardiac resynchronization therapy, heart failure, interventricular delay, left bundle branch block, reverse remodeling

\section{1 | INTRODUCTION}

Cardiac resynchronization therapy (CRT) reduces morbimortality and improves heart failure symptoms in appropriately selected candidates. ${ }^{1}$ The likelihood of nonresponse to CRT increases with ischemic cardiomyopathy (ICM), atypical left bundle branch block (LBBB), narrow QRS complex, and less activation delay at the site of left ventricular (LV) lead implant (QLV). ${ }^{2-4}$ Despite improvements in guiding LV lead implantation using both electrical and imaging strategies, ${ }^{5-7}$ the rate of nonresponse to CRT remains around one-third of the patients. In this context, underlying electrical patterns of nonresponse have been poorly described and electrocardiographic criteria (QRS duration and morphology) still remain insufficient to differentiate responders from nonresponders to CRT.

The working mechanism of CRT consists of restoring electromechanical ventricular synchrony. By definition, the potential for CRT response lies in the baseline electrical substrate inherent to the patient, but also in the electromechanical effect of biven tricular pacing. While most attempts to predict CRT response have focused on the patient's baseline electromechanical substrate, the role of pacing-induced electrical dyssynchrony has been poorly studied. ${ }^{8}$ However, understanding the interplay between baseline and pacing-induced dyssynchrony might be important to better predict nonresponse to CRT. Theoretically, one would expect the least pacing-induced left ventricular dyssynchrony (PLVD) and most homogeneous pacing-induced wavefront propagation when the right ventricular paced to left ventricular sensed delay (RVp-LVs) is similar to the left ventricular paced to right ventricular sensed delay (LVp-RVs). By contrast, asymmetrical paced-to-sensed delays may indicate a more heterogeneous ventricular activation compromising the potential benefits of CRT.

In the present study, we explored prospectively whether interlead paced-to-sensed delays recorded at the time of implant could predict a positive response to CRT. More precisely, we hypothesized that larger LV dyssynchrony during pacing can predict nonresponse. In addition, the relative contributions of baseline dyssynchrony and interlead paced-to-sensed delays to CRT response are studied in a more well-controlled in silico environment, using the well-validated CircAdapt model ${ }^{9-11}$ of the human heart and cardiovascular system.

\section{2 | METHODS}

\section{1 | Population and study protocol}

The study population consisted of 69 consecutive heart failure patients who received a CRT device based on current guideline indications. ${ }^{1}$ Only patients with New York Heart Association Functional Classification classes II-III or IV despite optimal medical therapy, left ventricular ejection fraction (LVEF) $\leq 35 \%$, and QRS duration $\geq 130 \mathrm{~ms}$ were included. CRT response was defined as a reduction in LV end-systolic volume $\geq 15 \%,{ }^{12}$ 6 months after implant compared to baseline. Patients with a previous implantable cardiac electronic device, below the age of 18 , congenital disease, and pregnant women were excluded from inclusion. Focal and diffuse fibrosis were assessed on cardiac magnetic resonance imaging (cMRI) when available before implantation. Typical LBBB electrocardiogram (ECG) criteria were based on Strauss and ESC 2013 classifications. ${ }^{13}$ The study was approved by our local ethics committee and all patients consented to participate in this study.

\section{2 | CRT implantation}

Transvenous CRT implantation was performed according to standard procedures. Right ventricular (RV) lead was positioned at the RV apex or in a midseptal position. Guided LV lead implantation was performed using coronary sinus venogram and the latest site of activation represented by QLV measurement was reached. The final LV lead position was confirmed if pacing thresholds were acceptable with a good LV lead stability and after excluding phrenic nerve stimulation. LV lead location was documented using anteroposterior, left and right anterior oblique fluoroscopic views, and defined as anterior, lateral or posterior, and apical, mid, or basal. Simultaneous biventricular stimulation was programmed and the atrioventricular delay was chosen to avoid A-wave truncation.

\section{3 | Intraoperative electrical delay assessment}

Electrical sensed and paced delays between the distal left bipole and the RV leads, as well as the QLV, were recorded using the device 
programmer (Abbott Merlin Pacing System Analyzer Model EX3100) at a sweep speed of $100 \mathrm{~mm} / \mathrm{s}$ (Figure 1). QLV was assessed by aligning the calipers with the onset of the QRS and the peak of the LV electrogram. RVs-LVs delays (ms) were measured between the peak in the RV electrogram and the peak in the LV electrogram during spontaneous rhythm. Paced interlead delays were defined as the conduction time (ms) from the LVp artifact to $\mathrm{RVs}$ electrogram and from the RVp artifact to LVs electrogram. Pacing was performed at the minimum rate that ensured complete ventricular capture (excluding fusion beats). Bipolar configuration was programmed for both pacing and sensing recordings. A standard pacing output of $5 \mathrm{~V} / 0.4 \mathrm{~ms}$ was applied. PLVD was defined as a situation where LVp-RVs is greater than RVp-LVs delays, indicating a more dyssynchronous activation of the LV during pacing. All delays were carefully reviewed and confirmed in all except one patient. Whenever possible (absence of phrenic nerve stimulation or inacceptable thresholds), measurements were performed from the distal bipole. In any cases, the initial LV configuration programming was the same as the one tested during the implant procedure.

\section{4 | Echocardiography}

Transthoracic echocardiography using an iE33 and an Epic ultrasound system (Philips Medical Systems; Andover, MA) with a 1- to $5-\mathrm{Hz}$ transthoracic transducer was performed at baseline and after a minimum of 6 months (range: 6-12 months) postimplant. LV volumes and LVEF were obtained using the biplane Simpson's method from four and two chambers' views. Measurements were obtained using the Philips IntelliSpace Cardiovascular Software (version 2.2). Offline analyses were performed by two independent observers (AG and $\mathrm{SL}$ ) and intraclass correlation coefficient between both was very good (0.86; 95\% Cl, 0.56-0.96).

\section{5 | Statistical analysis}

Continuous variables are reported as mean \pm standard deviation or median and interquartile range. A comparison between groups was performed using independent $t$ test when normally distributed or using the Kruskal-Wallis test if not. Categorical variables, expressed as counts and percentages, were compared using Fisher's exact test. All available clinical and electrocardiographic data (including all variables already identified in the literature as influencing the rate of response to CRT (age, sex, type of cardiomyopathy, LVEF, QRS duration, type of block, etc) were first used in a univariate regression analysis. All variables that correlated significantly $(P<.05)$ with the outcome (LVESV, $<-15 \%)$ were then entered into a multivariate logistic regression. The model was then evaluated using the $\chi^{2}$ to enter. $P<.05$ was considered as significant. Statistical analyses were done using IBM SPSS statistics software, version 25.0.

\section{6 | Computer simulations}

The CircAdapt computer model of the heart and circulation ${ }^{14}$ (MultiPatch Version) was used to evaluate the effect of baseline and paced dyssynchrony on acute hemodynamic response to pacing within the range measured in the patient population. Previous experimental and clinical studies have shown that the CircAdapt model realistically relates local ventricular myofiber mechanics to hemodynamics in the dyssynchronous failing heart. ${ }^{9}$

In the simulations, we tested different levels of PLVD by inducing latency at the LV pacing site. Latency is defined as the time difference between the LV stimulus and the actual myocardial capture. From previous research, it is known that latency is often longer at the epicardial LV pacing site compared to the endocardial RV pacing site. ${ }^{15}$ In the simulations, latency is modeled as an additional delay between LV stimulus and the regional onset of mechanical activation.

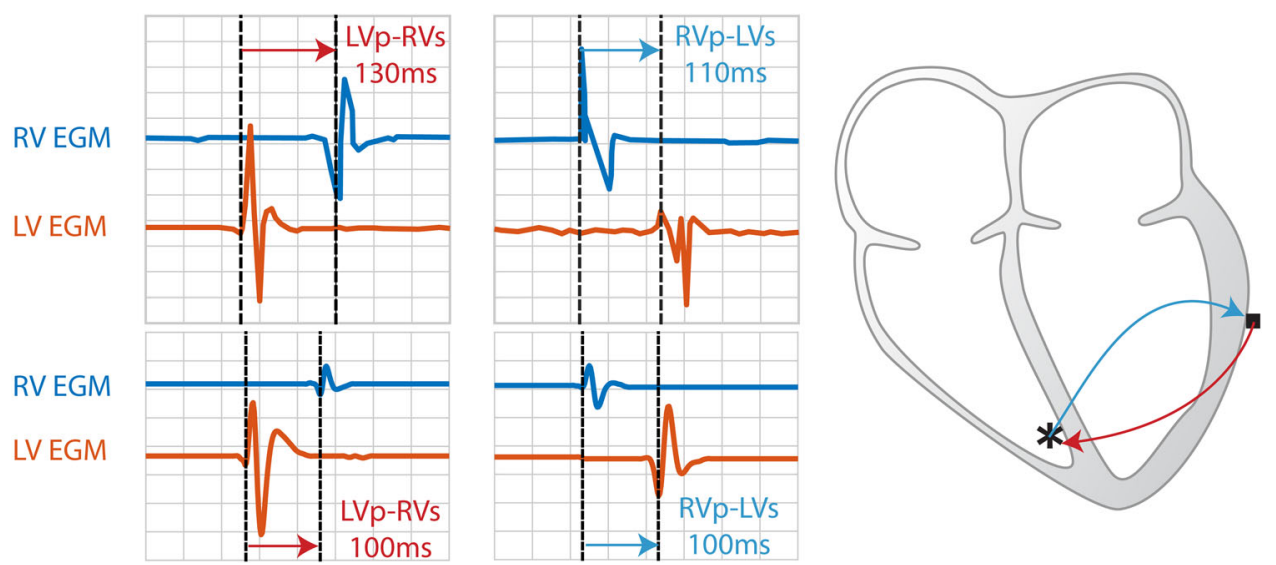

FIGURE 1 Intraoperatively measured RV (top) and LV (bottom) electrogram of RVp-LVs (blue arrow) and LVp-RVs (red arrow). Top shows an example of paced left ventricular dyssynchrony since LVp-RVs > RVp-LVs. Bottom shows an example of synchronous activation. LV-EGM, left ventricular electrogram; LVp-RVs, interval (ms) from left ventricular pacing to right ventricular sensed event on electrograms; PLVD, paced left ventricular dyssynchrony with (LVp-RVs) - (RVp-LVs) > 0; RV-EGM, right ventricular electrogram; RVp-LVs, interval (ms) from right ventricular pacing to left ventricular sensed event on electrograms 
Starting from a failing heart reference simulation, the LV total activation time was varied between 100 and $180 \mathrm{~ms}$ in steps of $10 \mathrm{~ms}$, resulting in nine baseline simulations. For each degree of baseline dyssynchrony, LV latencies from 0 to $50 \mathrm{~ms}$ (in steps of $5 \mathrm{~ms}$ ) were tested. The acute hemodynamic response was determined by calculating the change in maximum range in LV pressure rise ( $\mathrm{LV} \mathrm{dP/dt}$ max $)$ and cardiac output between the baseline and pacing simulations.

\section{3 | RESULTS}

\section{1 | Patient population}

Baseline characteristics of this study population, summarized in Table 1, are similar to other published CRT cohorts. Responders and nonresponders patients differed in terms of rate of nonischemic cardiomyopathy (NICM), typical LBBB, and QLV. Also, PLVD was present in significantly more nonresponders compared to responders $(P<.0001)$. More than two-thirds of nonresponders presented with PLVD. On a quantitative analysis, compared to baseline, change in left ventricular end-systolic volume was significantly lower with PLVD compared to no PLVD (Figure 2).

\section{2 | Intraoperative LV to RV interlead delays and CRT response}

As indicated in Table 2, intrinsic interlead electrical sensed delay (RVs-LVs) was not different between groups, whereas PLVD occurred

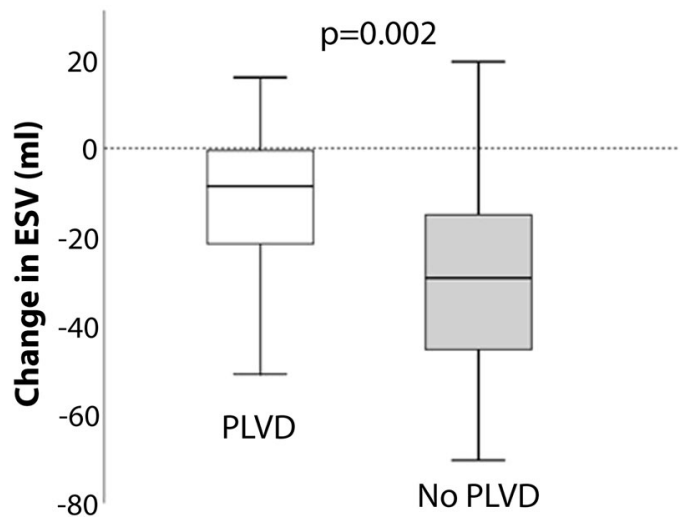

FIGURE 2 Comparison of the change in $\operatorname{LVESV}(\mathrm{mL})$ from baseline to 1-year postimplantation for the two patterns of delays (PLVD and no PLVD; ms). ESV, end-systolic volume; LVESV, left ventricular end-systolic volume $(\mathrm{mL})$; No PLVD, no paced left ventricular dyssynchrony with (LVp-RVs) - (RVp-LVs) $\leq 0$

more often in nonresponders. Because of atrioventricular block, no RVs-LVs measurements were available in 7 of the 69 patients.

In the nonresponse group, the pace-to-sense time was $15 \mathrm{~ms}$ longer for the LV compared to the RV. PLVD was associated with $\operatorname{ICM}(P=.005)$ but not with the type of LBBB (typical vs atypical), sex, QRS duration, nor LV and RV lead positions. In $20 \%$ of the patients, PLVD resulted from a shorter conduction time from the right during $\mathrm{RV}$ pacing compared to the intrinsic wavefront propagation (RVpLVs $<$ RVsLVs). A comparison of patient's characteristics with PLVD and those without is described in Table 3.

TABLE 1 Comparison of baseline characteristics between responders and nonresponders to CRT

\begin{tabular}{|c|c|c|c|c|}
\hline & Total cohort $(N=69)$ & Responders $(\mathrm{N}=39)$ & Nonresponders $(\mathrm{N}=30)$ & $P$ value* \\
\hline Age, y & $66(21)$ & $65(21)$ & $67(18)$ & .2 \\
\hline Sex (male, \%) & 70 & 61 & 80 & .1 \\
\hline NICM (\%) & 74 & 87 & 57 & .004 \\
\hline NYHA II-III (\%) & 85 & 87 & 83 & .7 \\
\hline Typical LBBB (\%) & 65 & 77 & 50 & .02 \\
\hline QRS duration, ms & $160(20)$ & $160(20)$ & $160(20)$ & .8 \\
\hline LVEF (\%) & $25 \pm 6$ & $24 \pm 6$ & $23 \pm 6$ & .9 \\
\hline LVEDV, $\mathrm{mL} / \mathrm{m}^{2}$ & $250(134)$ & $250(139)$ & 248 (129) & .4 \\
\hline LV pacing site lateral or posterolateral (\%) & 92.6 & 92 & 93 & .8 \\
\hline RV lead position (\%) & & & & .8 \\
\hline Midseptal & 25 & 26 & 23 & \\
\hline Apical & 75 & 74 & 77 & \\
\hline QLV, ms & $132 \pm 46$ & $150 \pm 50$ & $113 \pm 33$ & .03 \\
\hline QLV ratio ( $\geq 50 \%$ ) & 89 & $87(13 / 15)$ & $92(12 / 13)$ & .6 \\
\hline PLVD & $46 \%(N=31)$ & $26 \%(N=10)$ & $70 \%(N=21)$ & $<.0001$ \\
\hline
\end{tabular}

Note: Values are mean \pm SD or median (IQR).

Abbreviations: CRT, cardiac resynchronization therapy; ECG, electrocardiogram; IQR, interquartile range; LBBB, left bundle branch block; LV, left ventricular; LVEDV, left ventricular end-diastolic volume; LVEF, left ventricular ejection fraction; NICM, nonischemic cardiomyopathy; NYHA, New York Heart Association; PLVD, paced left ventricular dyssynchrony; QLV, interval (ms) from the onset of the QRS on the surface ECG to the first peak of left ventricular electrogram during sinus rhythm; RV, right ventricular.

${ }^{*} P<.05$ (Kruskal-Wallis test, independent $t$ test, or $\chi^{2}$ test). 
TABLE 2 Comparison of LV-RV delays at the time of implant between responders and nonresponders

\begin{tabular}{|c|c|c|c|c|}
\hline & Total cohort $(\mathrm{N}=68)$ & Responders $(\mathrm{N}=38$ ) & Nonresponders $(\mathrm{N}=30)$ & $P$ value* \\
\hline RVs-LVs & $82 \pm 44$ & $89 \pm 45$ & $72 \pm 40$ & .13 \\
\hline LVp-RVs & $120 \pm 41$ & $116 \pm 43$ & $126 \pm 38$ & .35 \\
\hline RVp-LVs & $115 \pm 37$ & $118 \pm 40$ & $111 \pm 34$ & .43 \\
\hline$(L V p-R V s)-(R V p-L V s)$ & $5 \pm 23$ & $-2 \pm 21$ & $14 \pm 23$ & .003 \\
\hline PLVD & $46 \%$ & $26 \%$ & $70 \%$ & $<.0001$ \\
\hline
\end{tabular}

Note: Values are mean $\pm \mathrm{SD}$.

Abbreviations: LV, left ventricular; LVp-RVs, interval (ms) from left ventricular pacing to right ventricular sensed event; PLVD, paced left ventricular dyssynchrony; RV, right ventricular; RVp-LVs, interval (ms) from right ventricular pacing to left ventricular sensed event; RVs-LVs, interval (ms) from right to left ventricular first peak event on electrograms in sinus rhythm.

${ }^{*} P<.005$ (independent $t$ test or $\chi^{2}$ test).

With univariate analysis, PLVD (OR, 6.5; 95\% Cl, 2.2-18.9; $P=.001)$ atypical LBBB (OR, 3.3; 95\% Cl, 1.2-9.4; $P=.022$ ), and ICM (OR, 5.2; $95 \% \mathrm{Cl}, 1.6-17 ; P=.006)$ were predictors for $\mathrm{CRT}$ nonresponse. With multivariate analysis, both PLVD (OR, 9.7; 95\% Cl, 2.8-33.9; $P<.0001)$ and atypical LBBB (OR, 5.6; $95 \% \mathrm{Cl}, 1.5-20.3 ; P=.009)$ were independent predictors of nonresponse (Table 4).

Accordingly, we developed an integrated statistical model that included synchronous activation of the LV during pacing (no PLVD) and the QRS morphology (typical LBBB). Our results show that compared to typical LBBB, only (which is the "first-line" screening tool

TABLE 3 Comparison of characteristics between patients with and without paced left ventricular dyssynchrony

\begin{tabular}{|c|c|c|c|}
\hline & $\begin{array}{l}\text { PVLD } \\
(N=31)\end{array}$ & $\begin{array}{l}\text { No PVLD } \\
(\mathrm{N}=37)\end{array}$ & P value* \\
\hline Age, y & $65(18)$ & $66(20)$ & .34 \\
\hline Sex (male, \%) & 74 & 67 & .5 \\
\hline NICM (\%) & 61 & 84 & .04 \\
\hline NYHA II-III (\%) & 87 & 80 & .7 \\
\hline Typical LBBB (\%) & 68 & 62 & .6 \\
\hline QRS duration, ms & $160(20)$ & $160(20)$ & .8 \\
\hline LVEF (\%) & $25 \pm 6$ & $24 \pm 6$ & .7 \\
\hline LVEDV, $\mathrm{mL} / \mathrm{m}^{2}$ & $260(140)$ & 243 (129) & .7 \\
\hline $\begin{array}{l}\text { LV pacing site } \\
\text { Lateral or } \\
\text { posterolateral (\%) }\end{array}$ & 92 & 93 & 1 \\
\hline $\begin{array}{l}\text { RV lead position (\%) } \\
\text { Midseptal } \\
\text { Apical }\end{array}$ & $\begin{array}{l}32 \\
68\end{array}$ & $\begin{array}{l}17 \\
83\end{array}$ & .1 \\
\hline QLV, ms & $122 \pm 47$ & $138 \pm 47$ & .4 \\
\hline QLV ratio ( $\geq 50 \%$ ) & 85 & 93 & .5 \\
\hline$\Delta \mathrm{ESV} \geq 15 \%(\%)$ & 32 & 76 & $<.0001$ \\
\hline
\end{tabular}

Note: Values are mean $\pm \mathrm{SD}$ or median (IQR).

Abbreviations: ESV, end-systolic volume; IQR, interquartile range; LBBB, left bundle branch block; LGE, late gadolinium enhancement; LV, left ventricular; LVEDV, left ventricular end-diastolic volume; LVEF, left ventricular ejection fraction; NICM, nonischemic cardiomyopathy; NYHA, New York Heart Association; PLVD, paced left ventricular dyssynchrony; $\mathrm{RV}$, right ventricular.

${ }^{*} P<.05$ (independent $t$ test, Kruskal-Wallis or $\chi^{2}$ tests). for clinicians to predict CRT response), a model integrating both no PLVD + typical LBBB had a better predictive value for CRT response $\left(\chi^{2}\right.$ to enter: 7.96; $\left.P<.005\right)$.

\section{3 | Relationship between interstitial fibrosis and necrosis and asymmetrical delays of conduction}

Interstitial fibrosis and necrosis in heart failure are common substrates associated with localized conduction abnormalities, including unidirectional slowing and block of conduction potentially explaining our findings. ${ }^{16,17}$ Accordingly, using cMRI, we investigated in 62 patients of our cohort whether PLVD was associated with a higher volume of focal (late gadolinium enhancement [LGE]) and diffuse fibrosis (extracellular volume [ECV]). Transmural LGE was present more often in patients with vs without PLVD (OR, 7.6; 95\% Cl, 1.5-38.8; $P=.01$ ). Although there was a trend for higher ECV in nonresponders, ECV was not associated with PLVD (OR, 0.9; 95\% $\mathrm{Cl}, 0.9-1 ; P=N S)$.

\section{4 | Simulated acute hemodynamic responses evaluation of the interplay of baseline dyssynchrony and interlead paced delays}

Simulated acute hemodynamic responses to different baseline and pacing-induced dyssynchronies are presented in Figures 3 and 4. Both LV dP/dt $t_{\max }$ and cardiac output had an increased response to CRT when introducing a larger degree of baseline dyssynchrony. For a given degree of baseline dyssynchrony, the maximal response was observed when no LV latency was introduced in the model. Increasing the LV latency was associated with deterioration of both parameters, which could be especially important in situations where baseline dyssynchrony was lower.

\section{4 | DISCUSSION}

In the present study, we explored prospectively whether pacinginduced electrical activation delays recorded at the time of implant 
TABLE 4 Predictors for CRT nonresponse at univariate and multivariate logistic regression analyses

\begin{tabular}{|c|c|c|c|c|}
\hline & \multicolumn{2}{|l|}{ Univariate analysis } & \multicolumn{2}{|l|}{ Multivariate analysis } \\
\hline & Odds ratio $(95 \% \mathrm{Cl})$ & $P$ value & Odds ratio $(95 \% \mathrm{Cl})$ & $P$ value \\
\hline Sex (male) & $2.6(0.86-7.88)$ & .089 & & \\
\hline Baseline LEVF & $0.98(0.91-1.06)$ & .76 & & \\
\hline QRS duration & $0.99(0.97-1.017)$ & .58 & & \\
\hline PLVD & $6.53(2.25-18.92)$ & .001 & $9.74(2.8-33.9)$ & $<.0001$ \\
\hline Atypical LBBB & $3.33(1.19-9.36)$ & .022 & $5.6(1.5-20.3)$ & .009 \\
\hline ICM & $5.2(1.6-17)$ & .006 & & \\
\hline
\end{tabular}

Abbreviations: $\mathrm{Cl}$, confidence interval; CRT, cardiac resynchronization therapy; ICM, ischemic cardiomyopathy; LBBB, left bundle branch block; LVEF, left ventricular ejection fraction; PLVD, paced left ventricular dyssynchrony.

could predict CRT response. More precisely, we hypothesized that asymmetrical conduction times when pacing alternatively from the LV and the RV leads can be used to predict LV reverse remodeling after CRT.

Our results can be summarized as follows:

- First, PLVD was strongly associated with the absence of LV reverse remodeling after CRT.

- Second, longer QLV values were associated with positive LV reverse remodeling. Where the presence of sufficient baseline dyssynchrony remains essential for a potential response, adding PLVD to a conventional statistical model based on QRS duration and morphology, significantly improved its predictive value.

- Third, computer simulations based on the range of dyssynchrony measured in the patient cohort confirmed that the level of pacinginduced electrical dyssynchrony modulates CRT response together with the baseline dyssynchrony.

\section{1 | PLVD better predicts CRT response because it incorporates the state of dyssynchrony during treatment}

A slower conduction velocity from the left is associated with nonresponse due to a decreased effectiveness of the resynchronization therapy. If pacing from the left to the right takes longer compared to the opposite, this results in a longer mean LV and total activation times, less synchronous activation, and acute response. From a clinical perspective, previous clinical studies already demonstrated that biventricular pacing provide CRT response mainly by reducing the interventricular dyssynchrony. Ploux et al ${ }^{18}$ demonstrated that effective biventricular pacing depends mainly on the reduction of ventricular electrical uncoupling (VEU). This electrical marker of dyssynchrony corresponds to the difference between the mean LV activation time minus the mean RV activation time during baseline and biventricular pacing. The more VEU is reduced the more hemodynamics acute benefit was observed with CRT. Our data not
FIGURE 3 Surface plots of the simulated acute changes in cardiac output (left) and LV dP/dt $\max$ (right) when going from baseline dyssynchrony to CRT pacing with variation of levels of baseline dyssynchrony (LVTAT 100-180 ms) and amount of latency at the LV pacing site (0-50 ms). CRT, cardiac resynchronization therapy; LV, left ventricular; LVTAT, left ventricular total activation time (ms)
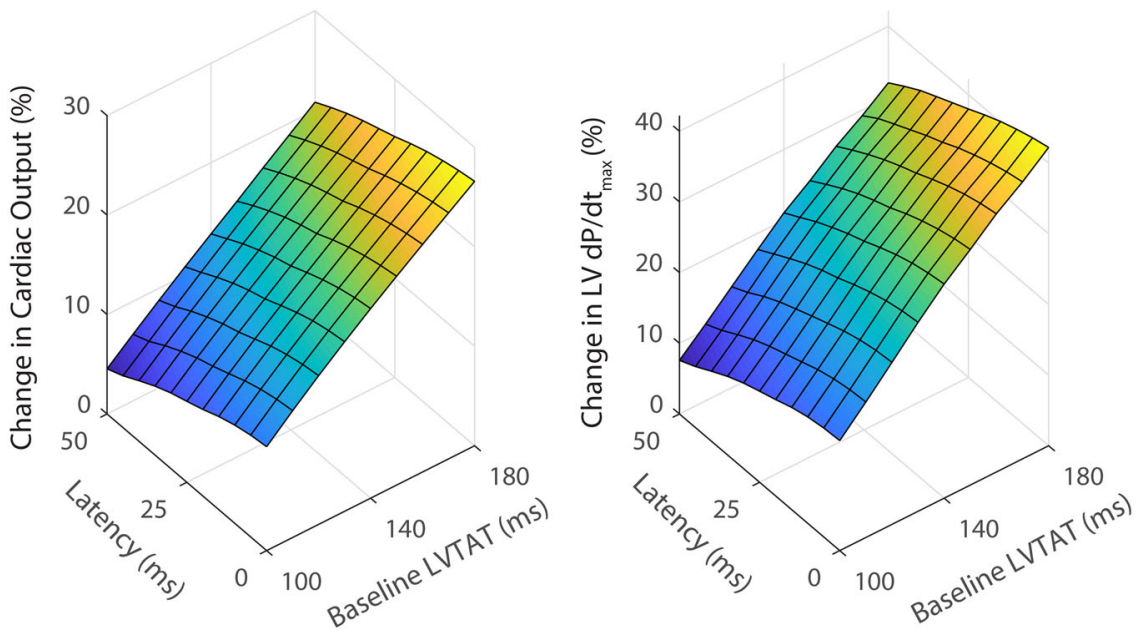

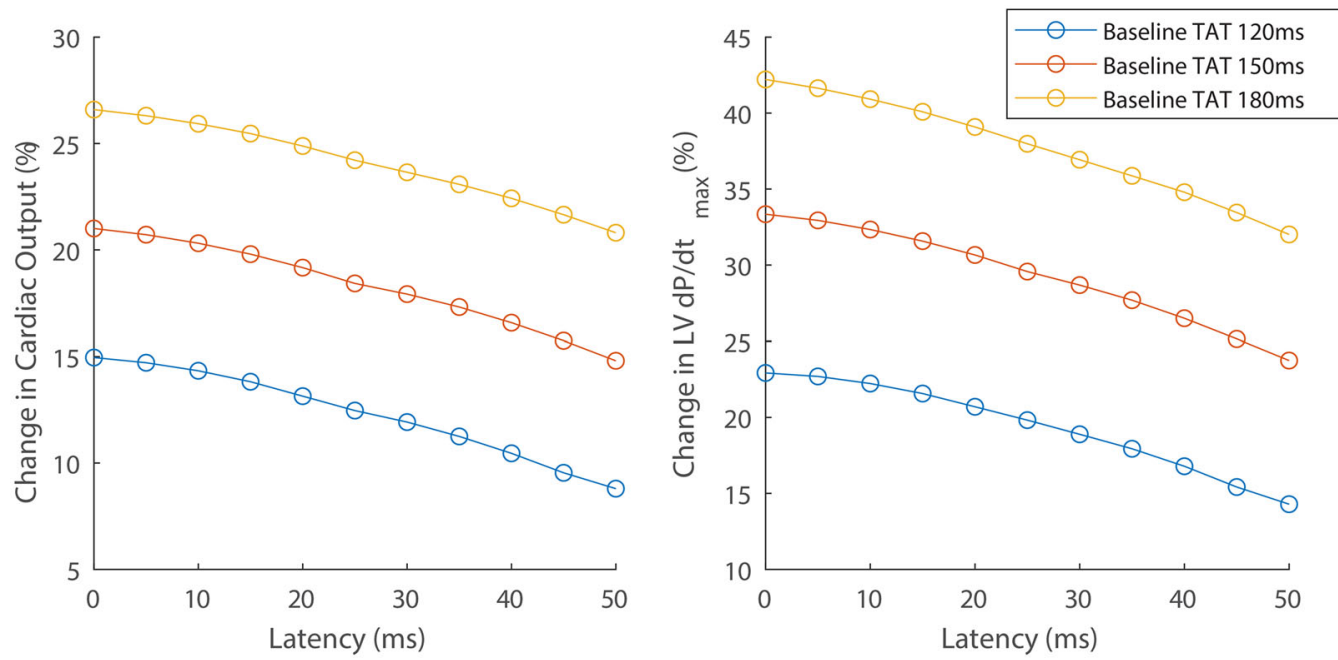

FIGURE 4 Simulated acute changes in cardiac output (left) and LV dP/dt $\max$ (right) when going from baseline dyssynchrony (left ventricular total activation time) to CRT pacing with different latencies at the LV pacing site $(0-50 \mathrm{~ms})$ during pacing. CRT, cardiac resynchronization therapy; LV, left ventricular; TAT, turnaround time

only confirm these results by pointing out the relative importance of both the intrinsic- and pacing-induced dyssynchrony but also demonstrate their implications for reverse remodeling and long-term clinical response. Hemodynamically, the acute increase in the cardiac output indicates that for the same cardiac output a lower preload is sufficient, lowering finally both the end-diastolic and end-systolic volumes.

\subsection{Anisotropic conduction properties as a cause of nonresponse to CRT}

From a pathophysiological point of view, anisotropic conduction properties in the heart are not uncommon. Epicardial pacing sites are associated with slurred initiation of the ventricular activation. And, in some circumstances, the initiation of the activation front might be retained from the pacing site. Previous studies ${ }^{19-21}$ demonstrated that changing pacing sites might create an intermittent line of functional block and reroute the depolarization front. This has been reported as a possible cause for prolonged activation times and nonresponse. In the present study, we confirmed using computer simulations that an increase in latency at the LV pacing site results in a decrease in acute hemodynamic response.

Transmural LGE and history of ICM were present more often in both the PLVD and CRT nonresponse group. Differences in activation alone might thus not be the only reason for the association of PLVD with nonresponse. It appears this intraoperatively obtained conduction difference could potentially be an indicator for the level of myocardial tissue damage. It has previously been shown in multiple studies that LV reverse structural remodeling occurs less in ICM vs patients with NICM receiving CRT. ${ }^{22}$

\subsection{Markers of intrinsic dyssynchrony in a population selected on guideline criteria}

By exploring the interplay between both the baseline dyssynchrony and the pacing-induced dyssynchrony, the difference of interlead delays unravels electrophysiological characteristics that are otherwise not appreciated by our routine practice. The results of this study also highlight that it is hard to find an improved measure for intrinsic dyssynchrony in a population that is selected based on the current CRT guidelines. In contrast to other studies, ${ }^{23-25}$ in our study population, neither the RVs-LVs nor QLV ratio ( $\geq 50 \%$ ) was significantly different between responders and nonresponders. Only the absolute QLV and typical LBBB differed significantly between both groups. The mean QLV also tended to be longer in patients without PLVD. Accordingly, results of the simulations indicated that a patient without PLVD might, therefore, show a larger acute response to pacing because this group has a relatively larger intrinsic dyssynchrony at baseline but also less paced dyssynchrony during biventricular pacing.

\section{4 | Clinical implications}

Predicting CRT response is essential for correctly choosing between CRT-P and CRT-D. ${ }^{1}$ Therefore, electrical measures using the pacing leads during implant might be important for improving the selection process of the device. Also, a better predictive model might be important for device optimization. Although not tested in the present study, patients with PLVD might benefit from LV pre-excitation, either through setting a ventriculoventricular pacing delay or LV-only pacing with optimal fusion. Additional studies are warranted to check if LV pre-excitation truly improve CRT response rate in patients with PLVD. 


\section{5 | LIMITATIONS}

This study has some limitations worth noting. First, values of intraoperative delays are limited by the precision of measurements made with the programmer nonetheless, in the present study, all the recording delays were measured not from the ventricular markers but on the local electrogram (sensed or paced). This contributed to reducing a potential bias induced by a possible delay between the marker and the onset of the ventricular event. Second, all patients had the RV lead implanted at midseptal or apical position, irrespective of the presence of an identified scar. However, pacedto-sensed interlead delay was not associated to RV or LV lead position in the patients. Measuring the latency based on a 12-lead ECG would also have been of interest. When defining endpoints and choosing criteria to define CRT response, we decided to use LV remodeling and end-systolic volume only. We did not evaluate the clinical response to CRT and did not perform functional tests. Therefore, we cannot exclude that patients without demonstrated reverse remodeling did not benefit clinically from CRT. ${ }^{26}$ Finally, since we did not have any information on the exact conduction wavefronts between the pacing sites, we chose to only simulate latency at the LV pacing site as source of PLVD. Other factors that can lead to PLVD, such as anisotropic conduction related to more remote or diffuse fibrosis, may result in similar interventricular activation dynamics and thereby acute hemodynamic response. Furthermore, the computer simulations only describe the acute hemodynamic response to CRT. Similarly, the presence of myocardial scar or ischemia has not been simulated in this study.

\section{6 | CONCLUSION}

In addition to the intrinsic electrical substrate, PLVD is strongly associated with less LV reverse remodeling, demonstrating that measuring the electrical substrate during pacing has additional value for prediction of CRT response in an already well-selected patient population. Computer simulations corroborate this finding by showing that, while intrinsic electrical dyssynchrony is a prerequisite, the level of pacing-induced dyssynchrony modulates acute CRT response.

\section{ORCID}

Anaïs Gauthey (D) http://orcid.org/0000-0003-4912-8753 Joost Lumens (D) http://orcid.org/0000-0001-8129-7384

\section{REFERENCES}

1. Brignole M, Auricchio A, Baron-Esquivias G, et al. ESC guidelines on cardiac pacing and cardiac resynchronization therapy: the task force on cardiac pacing and resynchronization therapy of the European Society of Cardiology (ESC). Developed in collaboration with the
European Heart Rhythm Association (EHRA). Eur Heart J. 2013; 2013(34):2281-2329.

2. Prinzen FW, Vernooy K, Auricchio A. Cardiac resynchronization therapy: state-of-the-art of current applications, guidelines, ongoing trials, and areas of controversy. Circulation. 2013;128:2407-2418.

3. Auricchio A, Prinzen FW. Non-responders to cardiac resynchronization therapy: the magnitude of the problem and the issues. Circ $J$. 2011;75:521-527.

4. Thibault B, Harel F, Ducharme A, et al. Cardiac resynchronization therapy in patients with heart failure and a QRS complex $<120$ milliseconds: the evaluation of resynchronization therapy for heart failure (LESSER-EARTH) trial. Circulation. 2013;127:873-881.

5. Gold MR, Birgersdotter-Green U, Singh JP, et al. The relationship between ventricular electrical delay and left ventricular remodelling with cardiac resynchronization therapy. Eur Heart J. 2011;32:25162524.

6. Stabile G, D'Onofrio A, Pepi P, et al. Interlead anatomic and electrical distance predict outcome in CRT patients. Heart Rhythm. 2015;12: 2221-2229.

7. Stephansen C, Sommer A, Kronborg MB, Jensen JM, Bouchelouche K, Nielsen JC. Electrically guided versus imaging-guided implant of the left ventricular lead in cardiac resynchronization therapy: a study protocol for a double-blinded randomized controlled clinical trial (ElectroCRT). Trials. 2018;19:600.

8. Sassone B, Gabrieli L, Sacca S, et al. Value of right ventricular-left ventricular interlead electrical delay to predict reverse remodelling in cardiac resynchronization therapy: the INTER-V pilot study. Europace. 2010;12:78-83.

9. Huntjens PR, Ploux S, Strik M, et al. Electrical substrates driving response to cardiac resynchronization therapy: a combined clinicalcomputational evaluation. Circ Arrhythm Electrophysiol. 2018;11: e005647.

10. Arts T, Delhaas T, Bovendeerd P, Verbeek X, Prinzen FW. Adaptation to mechanical load determines shape and properties of heart and circulation: the CircAdapt model. Am J Physiol: Heart Circ Physiol. 2005;288:H1943-H1954.

11. Lumens J, Ploux S, Strik M, et al. Comparative electromechanical and hemodynamic effects of left ventricular and biventricular pacing in dyssynchronous heart failure: electrical resynchronization versus left-right ventricular interaction. J Am Coll Cardiol. 2013;62:23952403.

12. Fornwalt BK, Sprague WW, BeDell P, et al. Agreement is poor among current criteria used to define response to cardiac resynchronization therapy. Circulation. 2010;121:1985-1991.

13. Caputo ML, van Stipdonk A, Illner A, et al. The definition of left bundle branch block influences the response to cardiac resynchronization therapy. Int J Cardiol. 2018;269:165-169.

14. Walmsley J, Arts T, Derval N, et al. Fast simulation of mechanical heterogeneity in the electrically asynchronous heart using the MultiPatch module. PLoS Comput Biol. 2015;11:e1004284.

15. Herweg B, Ali R, Ilercil A, et al. Site-specific differences in latency intervals during biventricular pacing: impact on paced QRS morphology and echo-optimized V-V interval. Pacing Clin Electrophysiol. 2010; 33:1382-1391.

16. Derval N, Duchateau J, Mahida S, et al. Distinctive left ventricular activations associated with ECG pattern in heart failure patients. Circ Arrhythm Electrophysiol. 2017;10:e005073.

17. Satoh $H$, Sano $M$, Suwa $K$, et al. Distribution of late gadolinium enhancement in various types of cardiomyopathies: significance in differential diagnosis, clinical features and prognosis. World J Cardiol. 2014;6:585-601.

18. Ploux S, Eschalier R, Whinnett Zl, et al. Electrical dyssynchrony induced by biventricular pacing: implications for patient selection and therapy improvement. Heart Rhythm. 2015;12:782-791. 
19. Ploux S, Lumens J, Whinnett Z, et al. Noninvasive electrocardiographic mapping to improve patient selection for cardiac resynchronization therapy: beyond QRS duration and left bundle branch block morphology. J Am Coll Cardiol. 2013;61: 2435-2443.

20. Auricchio A, Fantoni C, Regoli F, et al. Characterization of left ventricular activation in patients with heart failure and left bundlebranch block. Circulation. 2004;109:1133-1139.

21. Garrigue $S$, Bordachar $P$, Reuter $S$, Jais $P$, Haissaguerre $M$, Clementy J. Comparison of permanent left ventricular and biventricular pacing in patients with heart failure and chronic atrial fibrillation: a prospective hemodynamic study. Card Electrophysiol Rev. 2003;7:315-324.

22. Yokoshiki H, Mitsuyama H, Watanabe M, Mitsuhashi T, Shimizu A. Cardiac resynchronization therapy in ischemic and non-ischemic cardiomyopathy. J Arrhythm. 2017;33:410-416.

23. Gold MR, Singh JP, Ellenbogen KA, et al. Interventricular electrical delay is predictive of response to cardiac resynchronization therapy. JACC Clin Electrophysiol. 2016;2:438-447.

24. Zucchelli G, Soldati E, Di Cori A, et al. Role of intraoperative electrical parameters in predicting reverse remodelling after cardiac resynchronization therapy and correlation with interventricular mechanical dyssynchrony. Europace. 2010;12:1453-1459.

25. D'Onofrio A, Botto G, Mantica M, et al. Incremental value of larger interventricular conduction time in improving cardiac resynchronization therapy outcome in patients with different QRS duration. J Cardiovasc Electrophysiol. 2014;25:500-506.

26. Wikstrom G, Blomstrom-Lundqvist C, Andren B, et al. The effects of aetiology on outcome in patients treated with cardiac resynchronization therapy in the CARE-HF trial. Eur Heart J. 2009;30:782-788.

How to cite this article: Gauthey A, Willemen E, Lumens J, et al. Impact of paced left ventricular dyssynchrony on left ventricular reverse remodeling after cardiac resynchronization therapy. J Cardiovasc Electrophysiol. 2020;31:494-502. https://doi.org/10.1111/jce.14330 